Article

\title{
Preparation of Microcellular Foams by Supercritical Carbon Dioxide: A Case Study of Thermoplastic Polyurethane 70A
}

\author{
Yu-Ting Hsiao ${ }^{1}$, Chieh-Ming Hsieh ${ }^{2}$, Tsung-Mao Yang ${ }^{3}$ and Chie-Shaan Su ${ }^{1, *(D)}$ \\ 1 Department of Chemical Engineering and Biotechnology, National Taipei University of Technology, \\ Taipei 10608, Taiwan; evaeva168168@gmail.com \\ 2 Department of Chemical and Materials Engineering, National Central University, Taoyuan 32001, Taiwan; \\ hsiehcm@ncu.edu.tw \\ 3 Department of Chemical and Materials Engineering, Chung Cheng Institute of Technology, \\ National Defense University, Taoyuan 33551, Taiwan; tsungmao1004@gmail.com \\ * Correspondence: cssu@ntut.edu.tw
}

Citation: Hsiao, Y.-T.; Hsieh, C.-M.; Yang, T.-M.; Su, C.-S. Preparation of Microcellular Foams by Supercritical Carbon Dioxide: A Case Study of Thermoplastic Polyurethane 70A. Processes 2021, 9, 1650. https:// doi.org/10.3390/pr9091650

Academic Editor:

Eduardo Vivaldo-Lima

Received: 16 July 2021

Accepted: 8 September 2021

Published: 13 September 2021

Publisher's Note: MDPI stays neutral with regard to jurisdictional claims in published maps and institutional affiliations.

Copyright: (c) 2021 by the authors. Licensee MDPI, Basel, Switzerland This article is an open access article distributed under the terms and conditions of the Creative Commons Attribution (CC BY) license (https:// creativecommons.org/licenses/by/ $4.0 /)$

\begin{abstract}
In this study, a case study to produce microcellular foam of a commercial thermoplastic polyurethane (TPU) through the supercritical carbon dioxide $\left(\mathrm{CO}_{2}\right)$ foaming process is presented. To explore the feasibility of TPU in medical device and biomedical application, a soft TPU with Shore hardness value of $70 \mathrm{~A}$ was selected as the model compound. The effects of saturation temperature and saturation pressure ranging from 90 to $140{ }^{\circ} \mathrm{C}$ and 90 to 110 bar on the expansion ratio, cell size and cell density of the TPU foam were compared and discussed. Regarding the expansion ratio, the effect of saturation temperature was considerable and an intermediate saturation temperature of $100{ }^{\circ} \mathrm{C}$ was favorable to produce TPU microcellular foam with a high expansion ratio. On the other hand, the mean pore size and cell density of TPU foam can be efficiently manipulated by adjusting the saturation pressure. A high saturation pressure was beneficial to obtain TPU foam with small mean pore size and high cell density. This case study shows that the expansion ratio of TPU microcellular foam could be designed as high as 4.4 . The cell size and cell density could be controlled within $12-40 \mu \mathrm{m}$ and $5.0 \times 10^{7}-1.3 \times 10^{9}$ cells $/ \mathrm{cm}^{3}$, respectively.
\end{abstract}

Keywords: supercritical $\mathrm{CO}_{2}$; microcellular foam; thermoplastic polyurethane $70 \mathrm{~A}$

\section{Introduction}

Polymer foams are multiphase and porous materials, which provide specific properties such as low density, high porosity, excellent thermal insulation, good sound absorption and high specific strength. They have been used in various applications as separation media, controlled drug release carriers, tissue engineering scaffolds and structural materials [1-3]. Polymer foams can be produced by two approaches depending on either the chemical or physical blowing agent used. Chemical blowing agents such as azodicarbonamide, sodium bicarbonate and zinc carbonate are the molecules that decompose into gases at a high temperature condition in a polymer matrix to generate the porous structure [4]. On the other hand, physical blowing agents are gaseous substances which can be dissolved into the polymer matrix at an elevated pressure, then generate bubbles in the matrix through depressurization afterward. In biomedical application, utilization of the physical blowing agents is more favorable since it avoids the drawbacks of chemical blowing agents, such as the requirement of a high temperature operation and contamination problems in the produced foams [5]. However, traditional physical blowing agents like chlorofluorocarbons (CFCs) and hydrofluorocarbons (HFCs) still exhibit environmental concern and hazardous properties. Recently, supercritical fluids, and particularly carbon dioxide $\left(\mathrm{CO}_{2}\right)$, have been developed as an alternate physical blowing agent in the foaming process, and have been used in preparation of polylactide (PLA), poly methyl methacrylate (PMMA) and polycaprolactone (PCL) foam [6-10]. 
Thermoplastic polyurethane (TPU) is a multiblock copolymer which contains hard and soft segments. The physical properties of TPU, like rigidity, hardness, flexibility and elastomeric behavior, can be efficiently manipulated by varying the hard and soft segments. Microcellular TPU foams show many excellent performances such as high strength, high toughness, outstanding abrasion-resistance and well-defined elasticity. They have been used in electronics, sporting goods, footwear, automobiles and medical devices. Due to those excellent characteristics and its potential in practical applications, many efforts have been devoted to study the foaming behavior of TPU using supercritical $\mathrm{CO}_{2}$ in the literature. For example, Nofar et al. investigated the foaming behavior of TPU with different hard and soft segments [11,12]. Wang et al. used two foaming routes according to the foaming temperature to fabricate structurally tunable TPU foams with improved mechanical properties [13]. Wang et al. designed a microcellular TPU foam with excellent fluorescent performance for decorative purpose using fluorescent pigment as the additive [14]. Jiang et al. prepared TPU foam sheets using a mold foaming process and investigated the foaming behavior at different foaming temperatures [15]. Yeh et al. designed sub-microcellular to nanocellular TPU nanocomposite foams using nanoclay as the nucleation agent and then investigated the improvement of mechanical properties [16]. Liu et al. used the bead foaming process to generate the expandable TPU foam beads and investigated the effect of operating parameters [17]. Yeh et al. studied the approaches and mechanisms to generate nanocellular TPU foam [18]. Prasad et al. investigated the effect of polymer hardness, pore size and porosity on the performance of TPU-based chemical mechanical polishing pads [19]. Zhang et al. used the supercritical $\mathrm{CO}_{2}$ process to generate expanded thermoplastic polyurethane beads and then manufactured foam sheets by compression molding [20]. Recently, TPU foam has been treated as a potential material in biomedical applications as a porous scaffold, a lightweight shape memory medical device, a bioinspired artificial skin and an acoustic absorbing material [21-25]. Regarding the design of novel medical devices, such as the hearing protection device used in a noisy workplace, a low hardness TPU is more favorable since it provides high softness. However, the foaming study of low-hardness TPU is still limited in the literature. To explore the application of TPU in medical devices, in this study, a case study of supercritical foaming for a soft TPU with Shore hardness value of 70A is reported. Furthermore, the effect of foaming parameters on the properties of TPU foam are investigated and discussed.

\section{Materials and Methods}

Polyester-based TPU pellets with Shore hardness value of 70A (H-70AU) were purchased from Ho Hsiang Ching Co., Ltd. (Taichung, Taiwan). $\mathrm{CO}_{2}$, used as the foaming agent, was purchased from Yu Sheng Gas Co., Ltd. (New Taipei City, Taiwan) with a purity of $99 \%$. The received TPU pellets were processed by compounding to enhance the homogeneity of the TPU matrix. About $50 \mathrm{~g}$ of TPU pellets were dried at $80{ }^{\circ} \mathrm{C}$ for $16 \mathrm{~h}$ then compounded using a parallel twin-screw extruder (Process 11, ThermoFisher Scientific Co., Waltham, MA, USA) at $180^{\circ} \mathrm{C}$ and $100 \mathrm{rpm}$. Approximately $0.05 \mathrm{~g}$ TPU was cut from the compounded sample and dried at $80{ }^{\circ} \mathrm{C}$ for $16 \mathrm{~h}$ to remove moisture. The dried TPU sample was used to perform the supercritical $\mathrm{CO}_{2}$ foaming experiments. The experimental apparatus for the supercritical $\mathrm{CO}_{2}$ foaming process is shown in Figure 1. TPU samples were placed inside the high-pressure vessels (V-1 to V-3), then immersed into a thermostatic oil bath to maintain the saturation temperature. $\mathrm{CO}_{2}$ stream from a gas cylinder was pressurized by a syringe pump system to the desired saturation pressure, then fed into the high-pressure vessels. The saturation temperature and saturation pressure were kept constant for the saturation time. In our previous experiments, different saturation times from 1 to $3 \mathrm{~h}$ were investigated, and the effect of saturation time was negligible. A saturation time of $2 \mathrm{~h}$ was used in this case study. After the saturation step, the pressure in each high-pressure vessel was immediately released through the three-way ball valves (B-1 to B-3). The produced TPU foam was then immersed into a water bath at $0{ }^{\circ} \mathrm{C}$ to stabilize the cell structure. In this study, saturation temperature varied from 
90 to $140{ }^{\circ} \mathrm{C}$ while the saturation pressure was controlled within 90 to 110 bar. For a given saturation temperature and saturation pressure, three foaming experiments were performed in parallel in three individual high-pressure vessels (V-1 to V-3) to confirm the reproducibility of the supercritical $\mathrm{CO}_{2}$ foaming process.

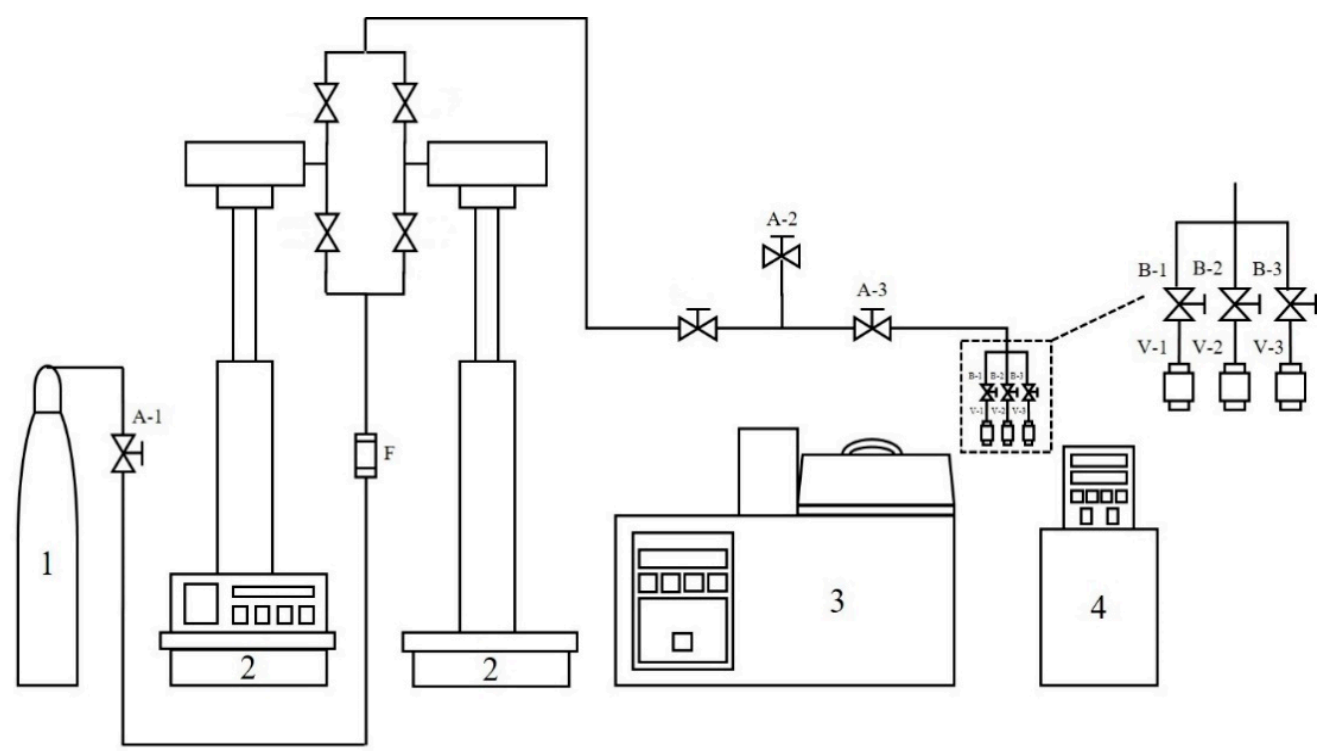

Figure 1. Experimental apparatus of supercritical $\mathrm{CO}_{2}$ foaming $\left(1: \mathrm{CO}_{2}\right.$ cylinder, 2: syringe pump system, 3: thermostatic oil bath, 4: circulating chiller, V: high-pressure vessel, F: filter, A: two-way needle valve, B: three-way ball valve).

Regarding the physical property characterization of TPU foam, scanning electronic microscope (SEM) was used to observe the cellular morphology of the foamed sample. The TPU sample was cryo-fractured using liquid nitrogen then sputter-coated with gold for SEM observation. The cell density was also assessed using SEM images from Image J software and estimated using the following equation.

$$
D=\left(\frac{N}{A}\right)^{1.5} \times\left(\frac{\rho_{p}}{\rho_{f}}\right)
$$

where $D, N, A$, are the cell density in cells $/ \mathrm{cm}^{3}$, the number of cells in the SEM images, and the actual measuring area of the SEM picture in $\mathrm{cm}^{2}$, respectively. $\rho_{p}$ and $\rho_{f}$ are the densities of the TPU sample before and after foaming, which were determined using a water-displacement method according to ASTM D792. With the measured densities, the expansion ratio $(E)$ of TPU foam can be calculated.

$$
E=\frac{\rho_{p}}{\rho_{f}}
$$

To understand the shrinkage behavior of the foamed TPU, the change of expansion ratio with time was also recorded. Accordingly, the shrinking ratio $(S)$ was then calculated from:

$$
S=\frac{E_{i}-E_{f}}{E_{i}} \times 100 \%
$$

$E_{i}$ is the expansion ratio just after foaming and $E_{f}$ is the final stable expansion ratio of the TPU foam after 5 days. In addition, the microstructure of TPU sample was also examined using differential scanning calorimetry (NETZSCH, DSC 200 F3) measurement. TPU samples were heated to $200{ }^{\circ} \mathrm{C}$ at a rate of $10^{\circ} \mathrm{C} / \mathrm{min}$. Next, the samples were cooled 
to $-85{ }^{\circ} \mathrm{C}$ at a rate of $5{ }^{\circ} \mathrm{C} / \mathrm{min}$. Finally, the samples were reheated to $200{ }^{\circ} \mathrm{C}$ at a rate of $10^{\circ} \mathrm{C} / \mathrm{min}$.

\section{Results and Discussion}

Design and preparation of TPU microcellular foam using supercritical $\mathrm{CO}_{2}$ was investigated in this case study. In our preliminary study, a TPU pellet received from the supplier was directly used as the raw material in the foaming experiments. However, the produced TPU foam eventually collapsed and showed obvious shrinkage and surface deterioration, as presented in Figure 2. Shrinkage is a common phenomenon in TPU foaming. In the foaming process, the rapid expansion stretches the molecular chains of TPU, resulting in internal stress in the produced foam. In addition, the blowing agent, $\mathrm{CO}_{2}$, has a high concentration in the produced foam and tends to diffuse out. These mechanisms consequently contribute to the shrinkage of TPU foam. To overcome the foam shrinkage problem, Zhang et al. blended acrylonitrile-butadiene-styrene (ABS) copolymer with TPU to reduce the shrinkage ratio [26]. Wang et al. blended different morphologies and contents of polytetrafluorethylene (PTFE) and discussed the effects on the shrinkage ratio of TPU [27]. Chen et al. developed a comprehensive model for discussing the shrinkage phenomenon of TPU foams [28]. Zhao et al. investigated the effect of foaming operating parameters using response surface methodology to screen the design space to generate TPU foam with a stable structure [29]. To deal with the foam shrinkage issue, a heat treatment by compounding the received TPU pellets was tested to enhance the homogeneity and modify the crystalline domain of the raw material. According to the DSC analysis of the received TPU pellet, a compounding temperature of $180{ }^{\circ} \mathrm{C}$ was used in this study. The surface morphology of the produced TPU foam from the compounded TPU pellet was also shown in Figure 2. As can be seen, the produced TPU foam shows less shrinkage. Thus, the compounded TPU pellet was then used as the raw material in our further foaming experiment.

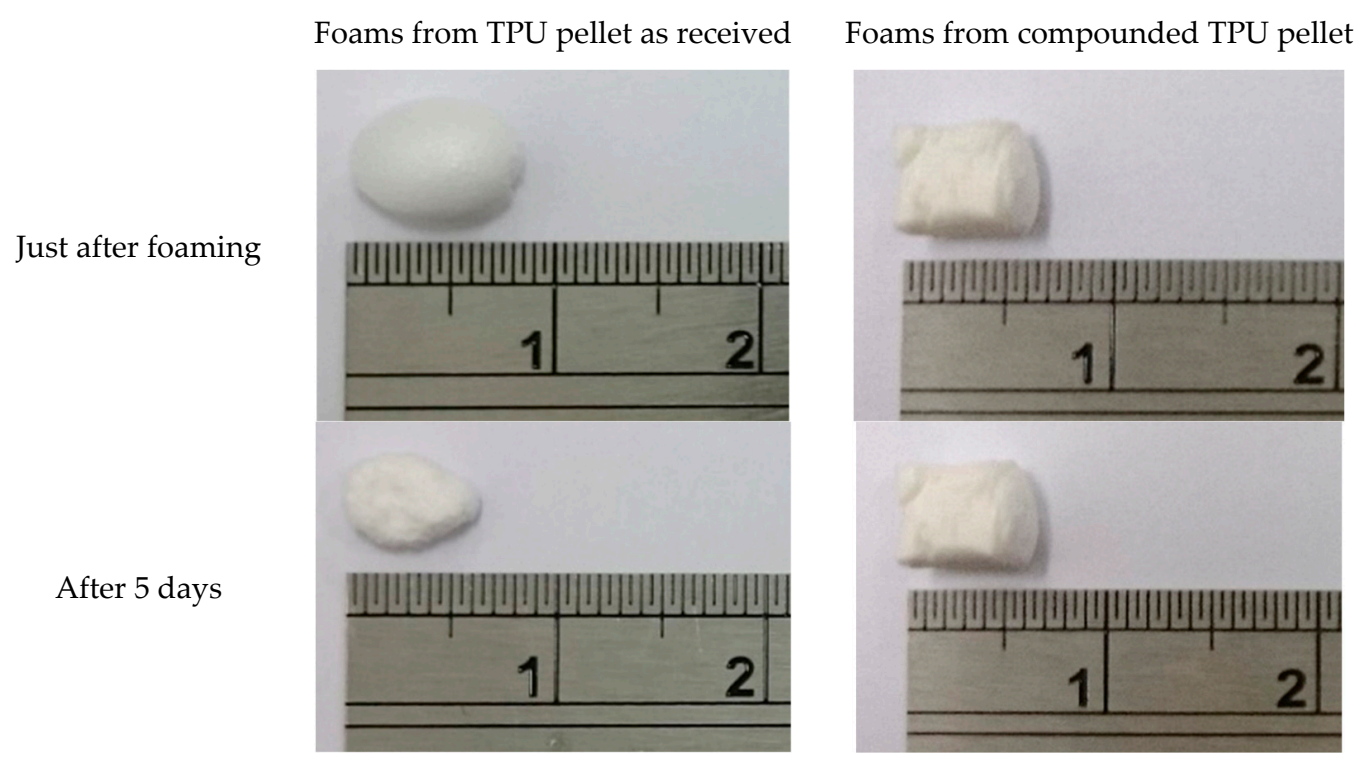

Figure 2. Comparison of surface morphology of produced foams from TPU pellet as received and compounded.

To further understand the effect of compounding in preventing foam shrinkage, DSC results of the TPU pellet as received and compounded TPU are graphically presented in Figure 3. TPU is a multi-block copolymer comprised of soft segment domains and hard segment domains. Crystallization behavior of the hard segment domains, which takes place via hydrogen bonds, has been identified as an important factor in controlling the foaming behavior. Crystallization and phase separation of hard segment domains may 
occur at different scales, from nanometric to micrometer-sized units. Thermal analysis, particularly differential scanning calorimetry (DSC), has been extensively used to investigate the structural differences of TPU $[30,31]$. As presented in Figure $3 a$, it is obvious that both TPUs (as received and compounded) exhibit multiple endothermic behavior by means of disordering of crystallites in different scales from a short-range to long-range order in the temperature interval from 120 to $180^{\circ} \mathrm{C}$. In addition, for the compounded TPU, an additional endothermic signal at $150{ }^{\circ} \mathrm{C}$ was found. During compounding using the twin-screw extruder, the mechanical shear should have broken the sequence of hard segment chains and stacked into different crystallite sizes. To further verify the modification of crystallization behavior of compounded TPU, Figure $3 b, c$ presents the comparison of cooling and the second heating of the DSC trace of the received and compounded TPU. As can be seen, the compounded TPU showed an earlier crystallization of hard segment domains than the as-received TPU. Furthermore, in the DSC second heating thermogram, the additional endothermic signal also appeared for the compounded TPU. According to the study of Hossieny et al. [32], after compounding, widely distributed hard segment chains may have better mobility with more closely packed phase-separated domains. The modification of microstructure after compounding shows earlier crystallization of hard segment domains and results in the additional endothermic peak. Due to the increased mobility of the hard segment domains after compounding, the internal stress attributed to the stretch of molecular chains during rapid expansion may be released, contributing to the beneficial effect on the production of TPU foam with less shrinkage.
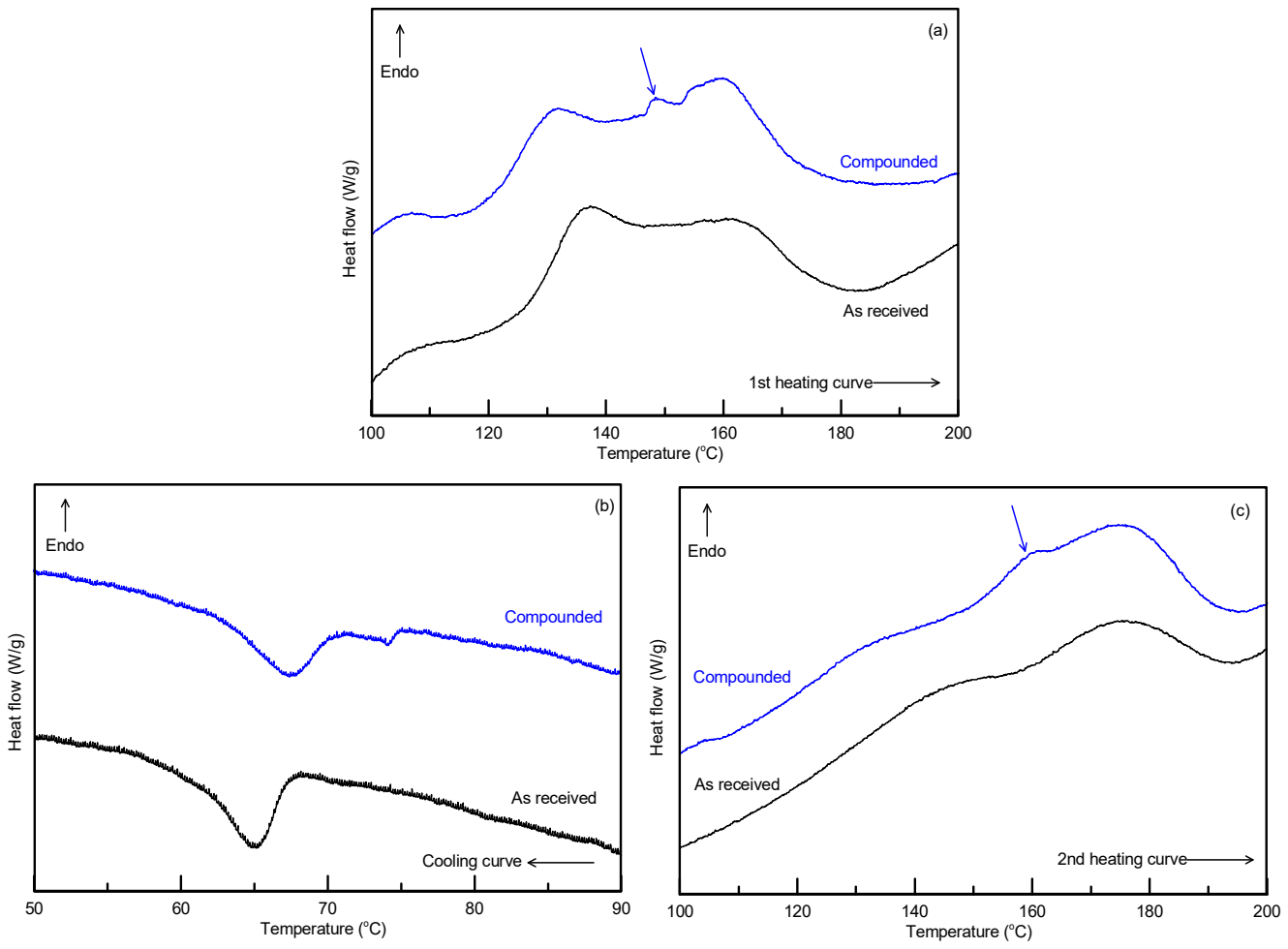

Figure 3. Comparison of DSC curves of TPU pellet as received and compounded: (a) first heating, (b) cooling and (c) second heating.

In this study, the effects of saturation temperature and saturation pressure in supercritical $\mathrm{CO}_{2}$ foaming process were studied and reported using the compounded TPU pellet as the raw material. To decide the appropriate saturation time, several foaming experiments were conducted using saturation times from 1 to $3 \mathrm{~h}$. The surface morphology and cell structure of the produced TPU foams from foaming experiments using different saturation time are presented in Figure 4. Accordingly, the consistent surface morphology and cell structure of TPU foam indicates that the effect of saturation time was negligible. Therefore, 
a saturation time of $2 \mathrm{~h}$ was finally used in our further foaming experiments. Table 1 lists 18 designed foaming conditions in this case study to investigate the effect of saturation temperature and saturation pressure on the expansion ratio, cell size and cell density of produced TPU microcellular foam. The saturation temperatures ranging from 90 to $140{ }^{\circ} \mathrm{C}$ and the saturation pressure varying from 90 to 110 bar were considered. The designed intervals of saturation temperature and saturation pressure have been commonly used in the literature for TPU foaming using supercritical $\mathrm{CO}_{2}[11-13,17]$. The expansion ratio, cell size and cell density of TPU foam obtained from different foaming conditions is also listed in Table 1. Each reported value was averaged from three parallel foaming experiments in individual high-pressure vessels (Figure 1, V-1-V-3) at the same foaming condition to confirm that our reported data were reproducible.

\section{Saturation time}

Surface morphology

$1 \mathrm{~h}$

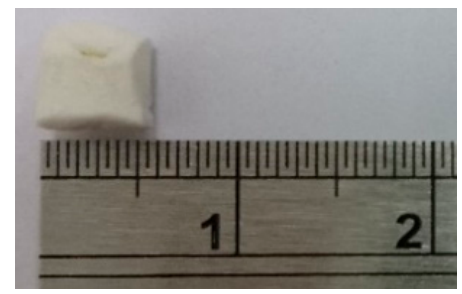

$2 \mathrm{~h}$

$3 \mathrm{~h}$
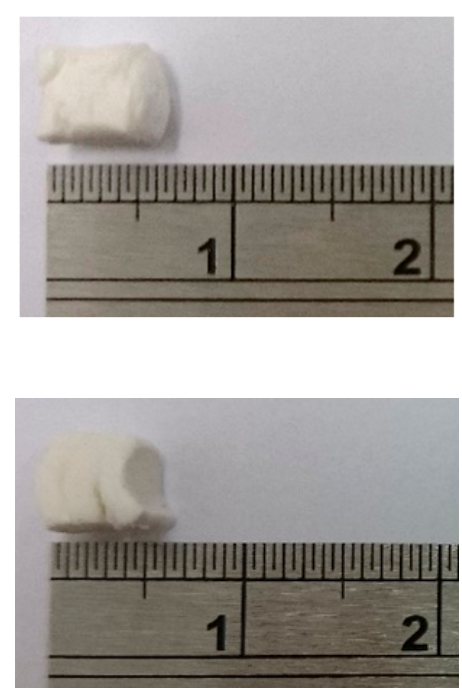

Cell structure

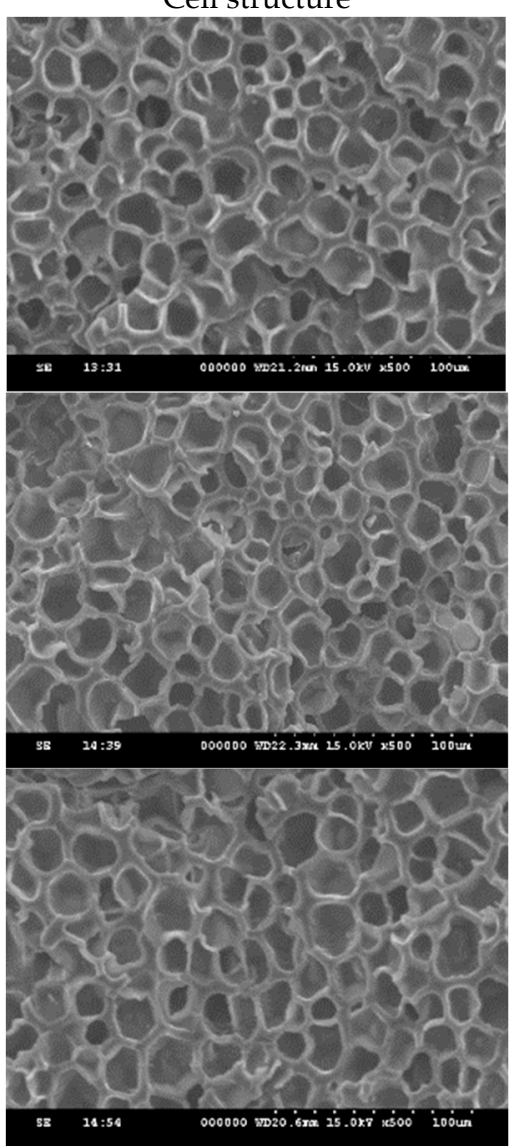

Figure 4. Comparison of surface morphology and cell structure of produced TPU foams from foaming experiments using saturation times of 1,2 and $3 \mathrm{~h}$.

To understand the synergistic influence on the surface morphology and expansion ratio, Figures 5 and 6 graphically present the surface morphology and expansion ratio of TPU foams obtained from foaming experiments using different saturation temperature and saturation pressure. Regarding the surface morphology shown in Figure 5, it can be seen that a low saturation temperature and a low saturation pressure were favorable to produce TPU foam with a smooth surface. As the saturation temperature increased, the surface morphology worsened, and the produced foam appeared to have surface deterioration and wrinkles. The deterioration of surface morphology may be caused by the low melt strength at a high temperature, especially for the low hardness TPU. When operating at a high saturation temperature, the TPU becomes more deformable, resulting in worse surface morphology $[13,15]$. Moreover, the adverse effect of high saturation temperature on surface morphology becomes obvious at higher saturation pressure. For example, when operating 
at a saturation pressure of 90 bar, the surface deterioration of TPU foam occurred when saturation temperature was above $120^{\circ} \mathrm{C}$. Once the saturation pressure increased to $110 \mathrm{bar}$, the phenomenon of surface deterioration appeared when saturation temperature was above $100{ }^{\circ} \mathrm{C}$. A higher saturation pressure increases the solubility of $\mathrm{CO}_{2}$ in TPU [33]. At this high $\mathrm{CO}_{2}$ solubility condition, a large quantity of $\mathrm{CO}_{2}$ escaped from the polymer during foaming and may have induced extensive and irreversible damage in the elastomers [34].
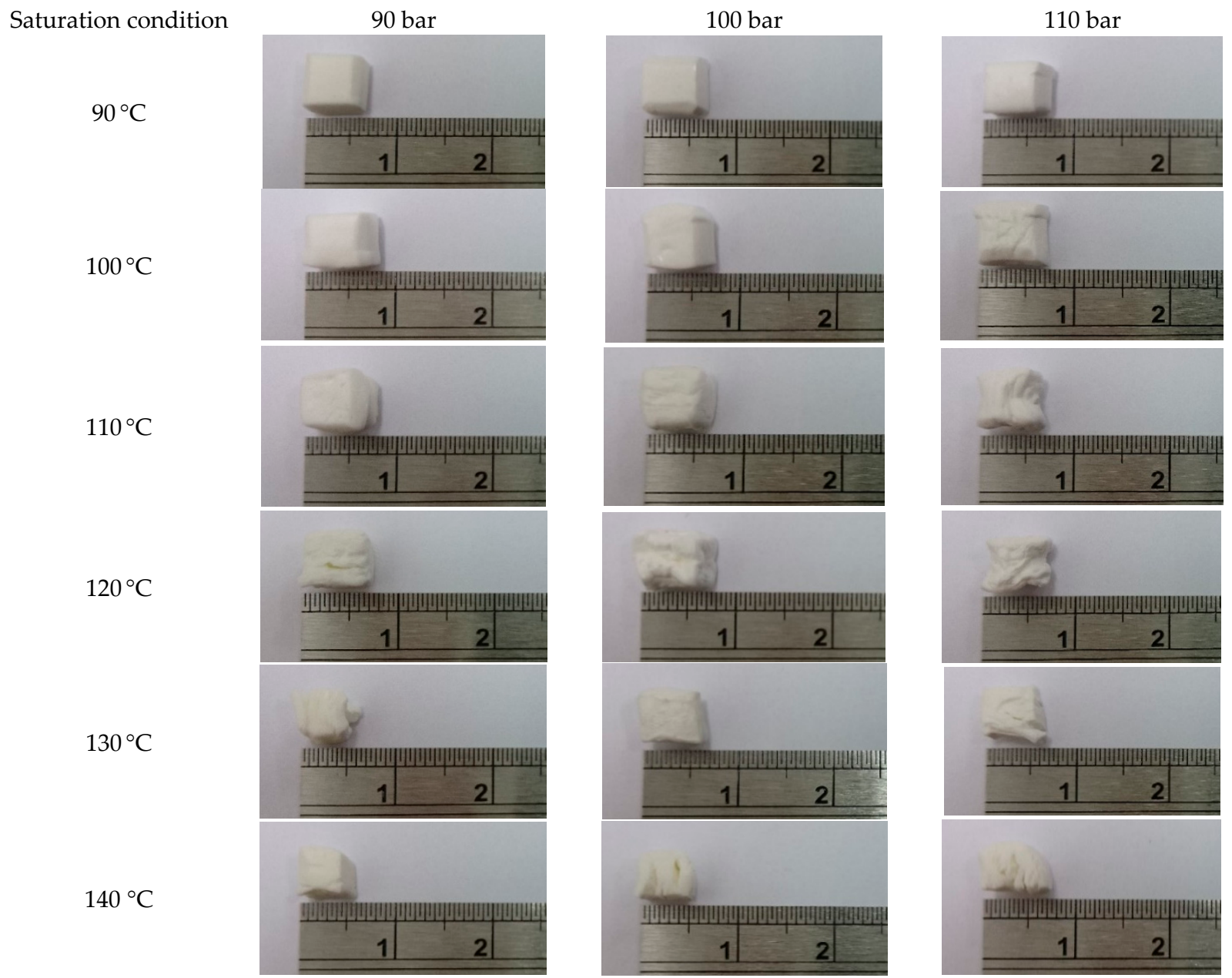

Figure 5. Comparison of surface morphology of TPU foams obtained from different saturation temperature and saturation pressure.

Table 1. Operating parameter and results of supercritical $\mathrm{CO}_{2}$ foaming of TPU.

\begin{tabular}{|c|c|c|c|c|c|c|}
\hline Exp. No. & $\mathbf{P}_{\text {sat }}$ (bar) & $\mathrm{T}_{\text {sat }}\left({ }^{\circ} \mathrm{C}\right)$ & $\begin{array}{l}\text { Expansion } \\
\text { Ratio (-) (a) }\end{array}$ & $\begin{array}{l}\text { Cell Size } \\
(\mu \mathrm{m})\end{array}$ & $\begin{array}{l}\text { Cell Density } \\
\left(10^{8} \text { Cells } / \mathrm{cm}^{3}\right)\end{array}$ & $\begin{array}{l}\text { Shrinking } \\
\text { Ratio (\%) }\end{array}$ \\
\hline 1 & 90 & 90 & 3.05 & 23.1 & 1.7 & 9.7 \\
\hline 2 & 90 & 100 & 4.43 & 28.9 & 1.5 & 5.8 \\
\hline 3 & 90 & 110 & 4.15 & 35.0 & 1.0 & -28.0 \\
\hline 4 & 90 & 120 & 3.79 & 40.1 & 0.5 & -18.8 \\
\hline 5 & 90 & 130 & 2.99 & 32.9 & 0.6 & -5.6 \\
\hline 6 & 90 & 140 & 1.76 & 20.7 & 0.6 & 1.3 \\
\hline 7 & 100 & 90 & 3.31 & 15.2 & 6.5 & 11.4 \\
\hline 8 & 100 & 100 & 4.19 & 19.2 & 5.3 & 3.1 \\
\hline 9 & 100 & 110 & 4.10 & 23.2 & 2.0 & -25.7 \\
\hline 10 & 100 & 120 & 3.43 & 29.4 & 1.2 & -2.7 \\
\hline 11 & 100 & 130 & 3.40 & 21.6 & 2.9 & 1.3 \\
\hline
\end{tabular}


Table 1. Cont.

\begin{tabular}{ccccccc}
\hline Exp. No. & $\mathbf{P}_{\text {sat }}(\mathbf{b a r})$ & $\mathbf{T}_{\text {sat }}\left({ }^{\circ} \mathbf{C}\right)$ & $\begin{array}{c}\text { Expansion } \\
\text { Ratio }(-)\end{array}$ & $\begin{array}{c}\text { Cell Size } \\
(\boldsymbol{\mu} \mathbf{m})\end{array}$ & $\begin{array}{c}\text { Cell Density } \\
\left(\mathbf{1 0}^{\mathbf{8}} \mathbf{C e l l s} / \mathbf{c m}^{\mathbf{3}}\right)\end{array}$ & $\begin{array}{c}\text { Shrinking } \\
\text { Ratio } \mathbf{( \% )}\end{array}$ \\
\hline 12 & 100 & 140 & 2.02 & 17.1 & 2.2 & -3.6 \\
13 & 110 & 90 & 3.27 & 12.4 & 13.0 & 13.4 \\
14 & 110 & 100 & 4.06 & 16.5 & 7.9 & 13.7 \\
15 & 110 & 110 & 3.75 & 16.6 & 6.9 & -9.6 \\
16 & 110 & 120 & 3.29 & 23.2 & 2.1 & -4.9 \\
17 & 110 & 130 & 3.06 & 19.3 & 3.8 & 0.5 \\
18 & 110 & 140 & 2.79 & 13.1 & 6.2 & -0.8 \\
\hline
\end{tabular}

(a) Final stable expansion ratio of the TPU foam.
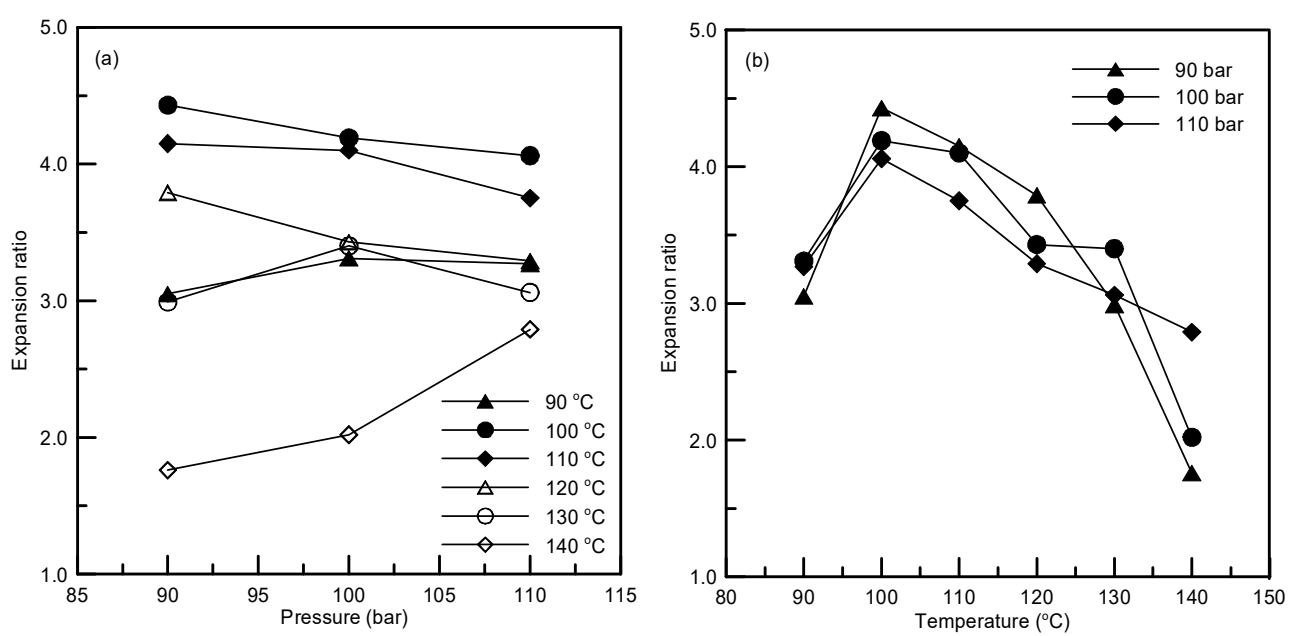

Figure 6. Effect of saturation condition on the expansion ratio of microcellular foam of TPU: (a) effect of saturation pressure, $(\mathbf{b})$ effect of saturation temperature.

On the other hand, Figure 6 presents the effect of the saturation condition on the expansion ratio of TPU. As can be seen, the effect of saturation temperature was more obvious than the saturation pressure, and a non-monotonic trend of expansion ratio with saturation temperature was found. The expansion ratio firstly increases and then decreases with increasing saturation temperature. A similar trend for the effect of saturation temperature on expansion ratio in TPU foaming was also reported by Nofar et al. and Wang et al. [11-13]. In general, increasing saturation temperature facilitates cell growth and leads to an increased expansion ratio of TPU foam. On the other hand, a further high saturation temperature decreases the melt strength of the TPU $/ \mathrm{CO}_{2}$ mixture. The decrease in melt strength accelerates gas loss leading to a reduced expansion ratio of TPU foam, and eventually increases the chance of cell coalescence and maximizes the possible surface deterioration. When the competitive mechanisms balanced, an intermediate saturation temperature of $100{ }^{\circ} \mathrm{C}$ was favorable to produce TPU foam with a stable expansion ratio higher than 4.0. In addition, the shrinking ratio listed in Table 1 also illustrates that the produced TPU foam from the saturation temperature of $100{ }^{\circ} \mathrm{C}$ was stable. The shrinking ratio of the produced foam was less than $10 \%$.

Figure 7 shows the cell structure of TPU foams obtained from different saturation temperature and saturation pressure. As can be seen, the TPU foam obtained in this case study exhibits a closed cell structure. According to the SEM images presented in Figure 7, the effect of saturation temperature and saturation pressure on the cell size and cell density of TPU foam is graphically illustrated in Figures 8 and 9, respectively. For the effect of saturation pressure at all saturation temperatures used in this study, a monotonic trend on the cell size and cell density was observed. Figures 8 and 9 demonstrate as the saturation pressure increased, the cell size decreased and the cell density increased. According to 
the experimental evidence reported by Li et al. and Primel et al. [33,35], the solubility of $\mathrm{CO}_{2}$ in the TPU is proportional to the increase of saturation pressure, which contributed to increasing the nucleation sites and resulting in the reduction of cell size and increase of cell density.

Saturation condition

$90{ }^{\circ} \mathrm{C}$

$100{ }^{\circ} \mathrm{C}$

$110{ }^{\circ} \mathrm{C}$

$120{ }^{\circ} \mathrm{C}$

$130{ }^{\circ} \mathrm{C}$

$140{ }^{\circ} \mathrm{C}$
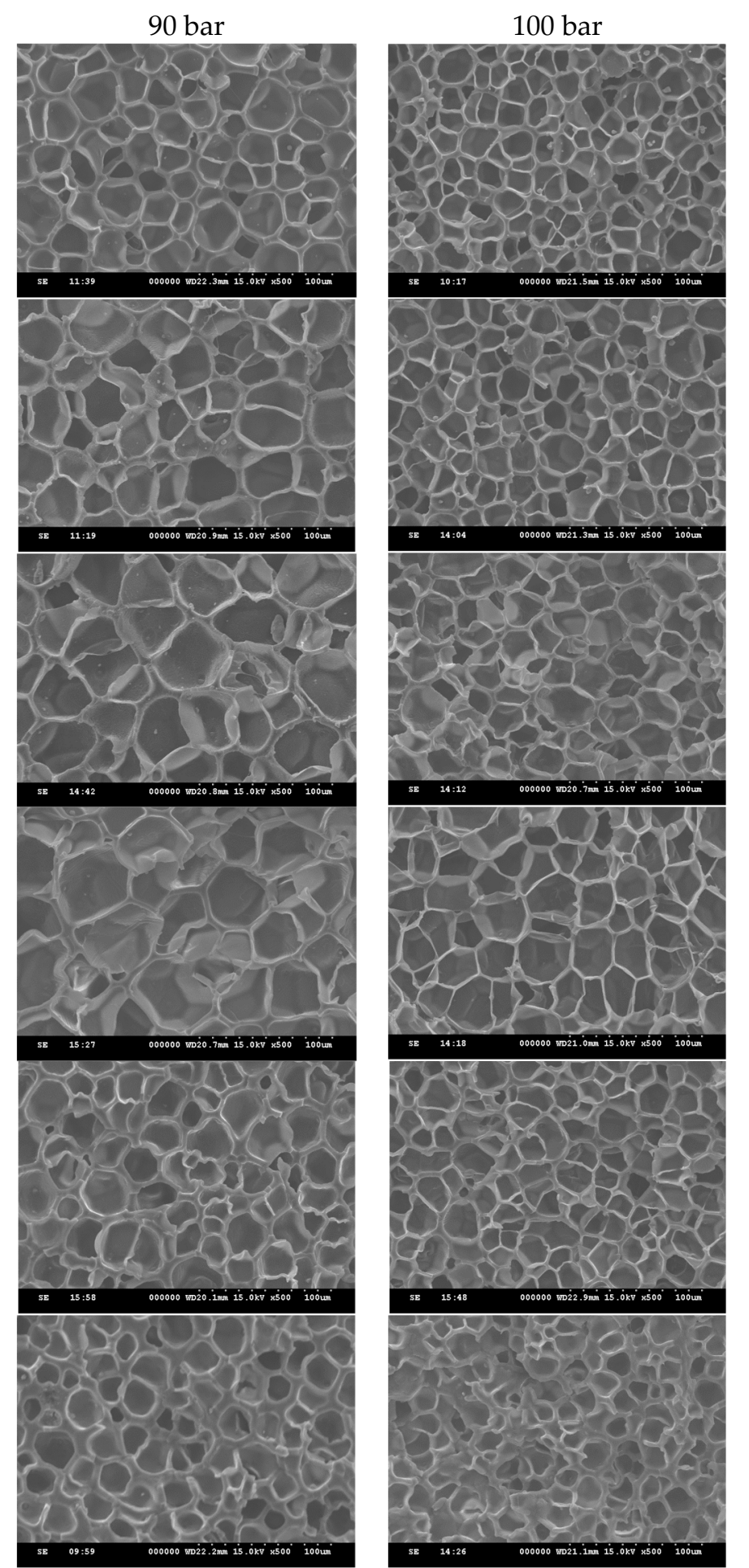

110 bar

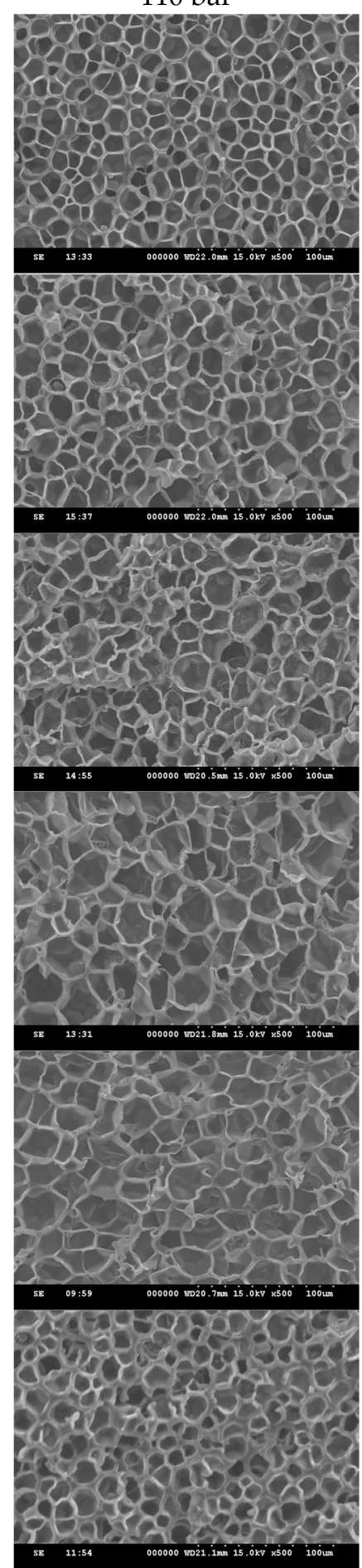

Figure 7. Comparison of cell structure of TPU foams obtained from different saturation temperature and saturation pressure. 

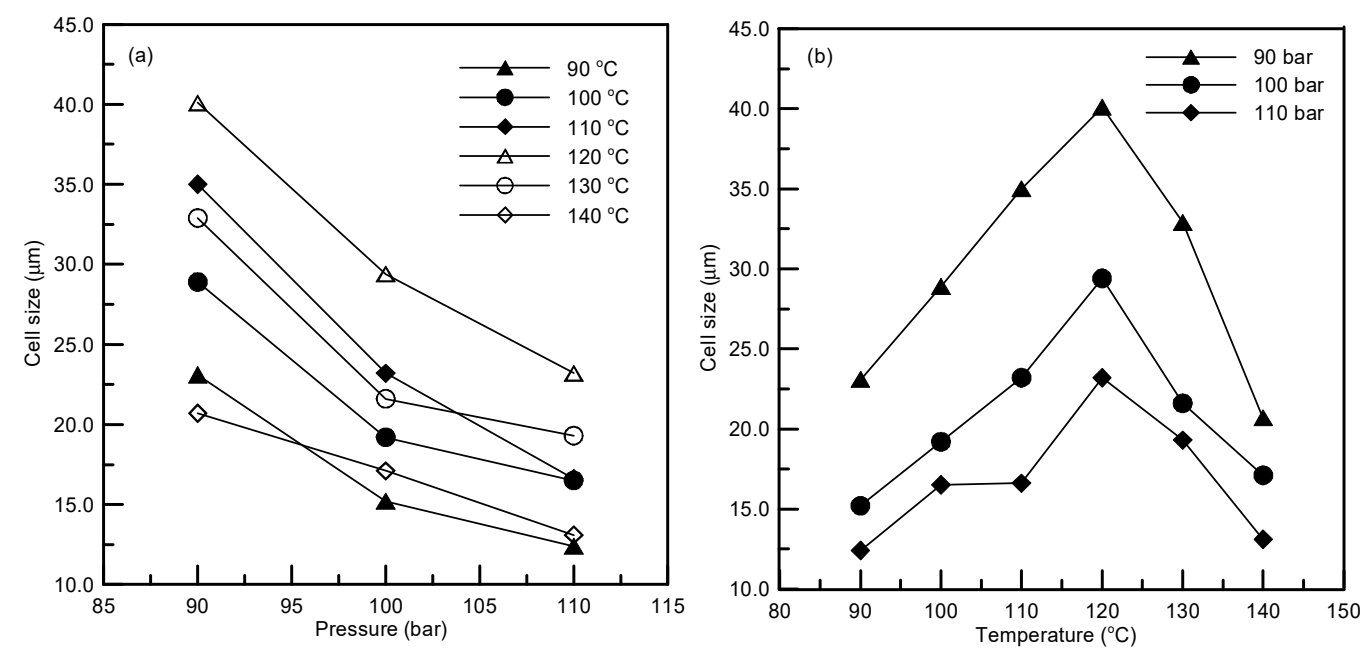

Figure 8. Effect of operating parameters on the cell size of microcellular foam of TPU: (a) effect of saturation pressure, (b) effect of saturation temperature.
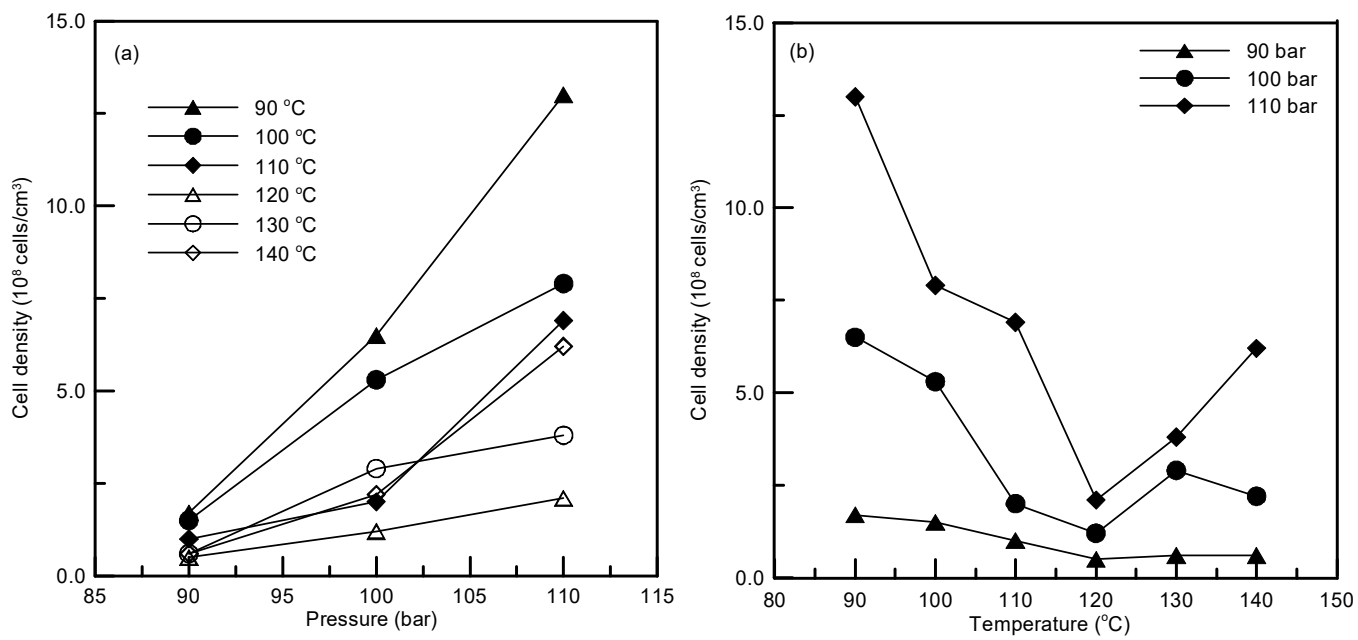

Figure 9. Effect of operating parameters on the cell density of microcellular foam of TPU: (a) effect of saturation pressure, (b) effect of saturation temperature.

As presented in Figures $8 \mathrm{~b}$ and $9 \mathrm{~b}$, a non-monotonic trend of the effect of saturation temperature on the cell size and cell density was observed. When operating at a low saturation temperature region $\left(90\right.$ to $\left.120^{\circ} \mathrm{C}\right)$, the cell size increased and cell density decreased as the saturation temperature increased. However, an opposite trend was found once the saturation temperature was set in a high temperature region $\left(120\right.$ to $\left.140{ }^{\circ} \mathrm{C}\right)$. TPU foam with small cell size and high cell density was produced along with the increase of saturation temperature. Similar observations for the effect of saturation temperature were also reported in the literature $[8,13,15]$. According to the study by Hossieny et al., thermal annealing of TPU could lead to rearrangement of hydrogen bonds and thus affect the crystallization behavior of hard segment domains. To understand the effect of saturation temperature on TPU microstructure, Figure 10 compares the DSC thermograms of produced TPU foam obtained from three saturation temperatures of 90,110 and $140{ }^{\circ} \mathrm{C}$. Obviously, the melting behavior of hard segment domains of TPU foam obtained from these three saturation temperatures was consistent, and the effect of saturation temperature on the TPU microstructure could be negligible. To further discuss the effect of saturation temperature on mean size and cell density, according to the literature solubility information [33,35], the solubility of $\mathrm{CO}_{2}$ dissolved in TPU would decrease as the saturation temperature increased, resulting in fewer nucleation sites in foaming. In addition, a high saturation temperature also facilitates 
cell growth during expansion. Furthermore, as the saturation temperature increases, the melt strength of the TPU $/ \mathrm{CO}_{2}$ decreases and TPU resin becomes more deformable. Along with the saturation temperature increase at a low temperature region $\left(90\right.$ to $\left.120^{\circ} \mathrm{C}\right)$, fewer nucleation sites, faster cell growth rate and more deformable characteristics result in a cell size increase and cell density reduction. On the other hand, when further increasing the saturation temperature to a high temperature region $\left(120\right.$ to $\left.140{ }^{\circ} \mathrm{C}\right)$, the melt strength of the TPU $/ \mathrm{CO}_{2}$ mixture decreases too low to maintain the foam structure. In addition, a fast $\mathrm{CO}_{2}$ exhausting from the TPU matrix attributes to the extremely low melt strength which may inhibit the cell growth and results in the production of TPU foam with worse surface morphology, less expansion ratio and small cell size.

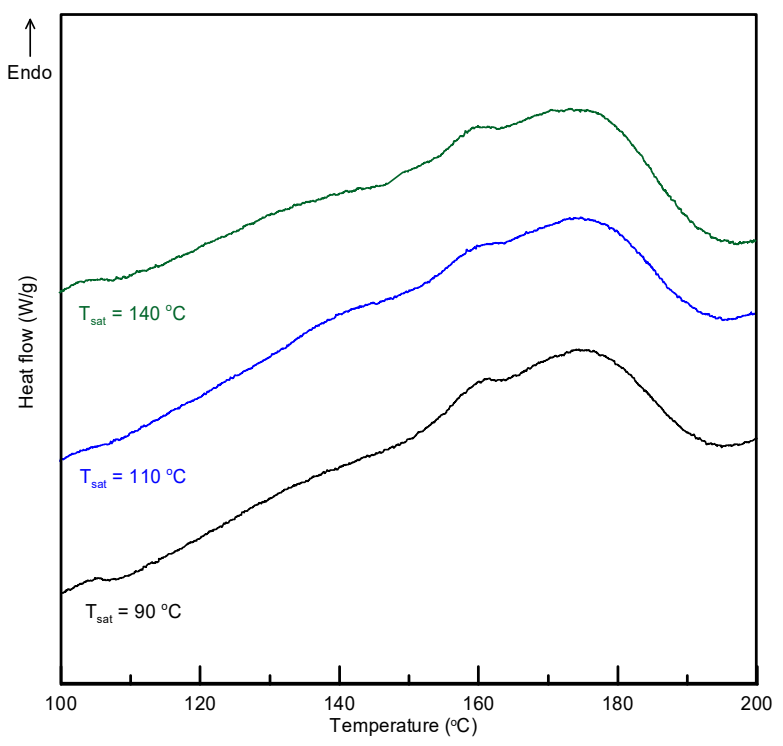

Figure 10. Comparison of DSC curves of produced TPU foam from different saturation temperatures.

\section{Conclusions}

To explore the application of TPU in biomedical applications, a case study to produce microcellular foams of a low hardness TPU with Shore hardness value of 70A using supercritical $\mathrm{CO}_{2}$ was presented. The effect of saturation temperature and saturation pressure ranging from $90-140^{\circ} \mathrm{C}$ and $90-110$ bar on the expansion ratio, cell size and cell density were investigated. Combining the operation at a low saturation temperature and a low saturation pressure, TPU foam with better surface morphology was successfully produced. In addition, for controlling the expansion ratio of TPU foam, the effect of saturation temperature was considerable. An intermediate saturation temperature of $100^{\circ} \mathrm{C}$ was favorable for producing the stable microcellular foam of TPU with an expansion ratio higher than 4.0. Furthermore, the cell size and cell density of the generated microcellular foam can be efficiently manipulated within $12-40 \mu \mathrm{m}$ and $5.0 \times 10^{7}-1.3 \times 10^{9} \mathrm{cells} / \mathrm{cm}^{3}$ by adjusting the saturation pressure. A high saturation pressure was beneficial to produce TPU microcellular foam with high cell density and small cell size. This study demonstrates the feasibility and controllability of producing low hardness TPU microcellular foam using supercritical $\mathrm{CO}_{2}$.

Author Contributions: Conceptualization, C.-S.S.; methodology, Y.-T.H.; investigation, Y.-T.H.; data curation, Y.-T.H.; writing — original draft preparation, C.-S.S.; writing—review and editing, T.-M.Y. and C.-M.H.; supervision, C.-S.S. All authors have read and agreed to the published version of the manuscript.

Funding: This research was funded by National Defense Industrial Development Foundation and Ministry of Science and Technology Taiwan (MOST 108-2221-E-027-069-MY3). 
Data Availability Statement: The data that support the findings of this study are available from the corresponding author upon reasonable request.

Conflicts of Interest: The authors declare no conflict of interest.

\section{References}

1. Sarver, J.A.; Kiran, E. Foaming of polymers with carbon dioxide-The year-in-review-2019. J. Supercrit. Fluids 2021, $173,105166$. [CrossRef]

2. Chauvet, M.; Sauceau, M.; Fages, J. Extrusion assisted by supercritical $\mathrm{CO}_{2}$ : A review on its application to biopolymers. J. Supercrit. Fluids 2017, 120, 408-420. [CrossRef]

3. Di Maioa, E.; Kiran, E. Foaming of polymers with supercritical fluids and perspectives on the current knowledge gaps and challenges. J. Supercrit. Fluids 2018, 134, 157-166. [CrossRef]

4. Jiménez, J.A.V.; Le Moigne, N.; Bénézet, J.C.; Sauceau, M.; Sescousse, R.; Fages, J. Foaming of PLA composites by supercritical fluid-assisted processes: A review. Molecules 2020, 25, 3408. [CrossRef] [PubMed]

5. Jin, F.L.; Zhao, M.; Park, M.; Park, S.J. Recent trends of foaming in polymer processing: A review. Polymers 2019, 11, 953. [CrossRef] [PubMed]

6. Li, B.; Zhao, G.; Wang, G.; Zhang, L.; Gong, J.; Shi, Z. Biodegradable PLA/PBS open-cell foam fabricated by supercritical CO 2 foaming for selective oil-adsorption. Sep. Purif. Technol. 2021, 257, 117949. [CrossRef]

7. Zhang, R.; Chen, J.; Zhu, Y.; Zhang, J.; Luo, G.; Cao, P.; Shen, Q.; Zhang, L. Correlation between the structure and compressive property of PMMA microcellular foams fabricated by supercritical $\mathrm{CO}_{2}$ foaming method. Polymers 2020, 12, 315. [CrossRef]

8. Li, B.; Ma, X.; Zhao, G.; Wang, G.; Zhang, L.; Gong, J. Green fabrication method of layered and open-cell polylactide foams for oil-sorption via pre-crystallization and supercritical CO2-inducedmelting. J. Supercrit. Fluids 2020, 162, 104854. [CrossRef]

9. Hatami, T.; Johner, J.C.F.; Cappuccio de Castro, K.; Mei, L.H.I.; Vieira, M.G.A.; Meireles, M.A.A. New insight into a step-by-step modeling of supercritical $\mathrm{CO}_{2}$ foaming to fabricate poly(E-caprolactone) scaffold. Ind. Eng. Chem. Res. 2020, 59, 20033-20044. [CrossRef]

10. Song, C.; Luo, Y.; Liu, Y.; Li, S.; Xi, Z.; Zhao, L.; Cen, L.; Lu, E. Fabrication of PCL scaffolds by supercritical $\mathrm{CO}_{2}$ foaming based on the combined effects of rheological and crystallization properties. Polymers 2020, 12, 780. [CrossRef]

11. Nofar, M.; Küçük, E.B.; Batı, B. Effect of hard segment content on the microcellular foaming behavior of TPU using supercritical $\mathrm{CO}_{2}$. J. Supercrit. Fluids 2019, 153, 104590. [CrossRef]

12. Nofar, M.; Batı, B.; Küçük, E.B.; Jalali, A. Effect of soft segment molecular weight on the microcellular foaming behavior of TPU using supercritical $\mathrm{CO}_{2}$. J. Supercrit. Fluids 2020, 160, 104816. [CrossRef]

13. Wang, G.; Wan, G.; Chai, J.; Li, B.; Zhao, G.; Mu, Y.; Park, C.B. Structure-tunable thermoplastic polyurethane foams fabricated by supercritical carbon dioxide foaming and their compressive mechanical properties. J. Supercrit. Fluids 2019, 149, 127-137. [CrossRef]

14. Wang, S.; Xue, S.; Ge, C.; Ren, Q.; Zhao, D.; Zhai, W. Preparation of fluorescent thermoplastic polyurethane microcellular foam films blown by supercritical $\mathrm{CO}_{2}$. J. Cell. Plast. 2019, 55, 483-505. [CrossRef]

15. Jiang, X.; Zhao, L.; Feng, L.; Chen, C. Microcellular thermoplastic polyurethanes and their flexible properties prepared by mold foaming process with supercritical $\mathrm{CO}_{2}$. J. Cell. Plast. 2019, 55, 615-631. [CrossRef]

16. Yeh, S.K.; Liu, Y.C.; Chu, C.C.; Chang, K.C.; Wang, S.F. Mechanical properties of microcellular and nanocellular thermoplastic polyurethane nanocomposite foams created using supercritical carbon dioxide. Ind. Eng. Chem. Res. 2017, 56, 8499-8507. [CrossRef]

17. Liu, X.; Wei, C.; Deng, X.; Cao, X. Comparative study on foaming process of thermoplastic polyester and polyether polyurethane with supercritical CO2 as foaming agent. Polym. Plast. Technol. Mater. 2020, 59, 457-468. [CrossRef]

18. Yeh, S.K.; Chen, Y.R.; Kang, T.W.; Tseng, T.J.; Peng, S.P.; Chu, C.C.; Rwei, S.P.; Guo, W.J. Different approaches for creating nanocellular TPU foams by supercritical $\mathrm{CO}_{2}$ foaming. J. Polym. Res. 2018, 25, 30. [CrossRef]

19. Prasad, A.; Fotou, G.; Li, S. The effect of polymer hardness, pore size, and porosity on the performance of thermoplastic polyurethane-based chemical mechanical polishing pads. J. Mater. Res. 2013, 28, 2380-2393. [CrossRef]

20. Zhang, T.; Lee, S.J.; Yoo, Y.H.; Park, K.H.; Kang, H.J. Compression molding of thermoplastic polyurethane foam sheets with beads expanded by supercritical $\mathrm{CO}_{2}$ foaming. Polymers 2021, 13, 656. [CrossRef] [PubMed]

21. Wendels, S.; Avérous, L. Biobased polyurethanes for biomedical applications. Bioact. Mater. 2021, 6, 1083-1106. [CrossRef] [PubMed]

22. Wang, W.; Liao, X.; Guo, F.; Wang, G.; Yan, Z.; Liu, F.; Li, G. Facile fabrication of lightweight shape memory thermoplastic polyurethane/polylactide foams by supercritical carbon dioxide foaming. Ind. Eng. Chem. Res. 2020, 59, 7611-7623. [CrossRef]

23. Li, H.; Sinha, T.K.; Oh, J.S.; Kim, J.K. Soft and flexible bilayer thermoplastic polyurethane foam for development of bioinspired artificial skin. ACS Appl. Mater. Interfaces 2018, 10, 14008-14016. [CrossRef]

24. Janik, H.; Marzec, M. A review: Fabrication of porous polyurethane scaffolds. Mater. Sci. Eng. C 2015, 48, 586-591. [CrossRef]

25. Li, T.T.; Lou, C.W.; Huang, C.H.; Huang, C.L.; Lin, J.H. Thermoplastic polyurethanes/polyester/polypropylene composites: Effect of thermoplastic polyurethanes honeycomb structure on acoustic-absorbing and cushioning property. J. Ind. Text. 2016, 46, 578-595. [CrossRef] 
26. Zhang, R.; Huang, K.; Hu, S.; Liu, Q.; Zhao, X.; Liu, Y. Improved cell morphology and reduced shrinkage ratio of ETPU beads by reactive blending. Polym. Test. 2017, 63, 38-46. [CrossRef]

27. Wang, W.; Liao, X.; He, Y.; Li, J.; Jiang, Q.; Li, G. Thermoplastic polyurethane/polytetrafluoroethylene composite foams with enhanced mechanical properties and anti-shrinkage capability fabricated with supercritical carbon dioxide. J. Supercrit. Fluids 2000, 163, 104861. [CrossRef]

28. Chen, Y.; Li, D.; Zhang, H.; Ling, Y.; Wu, K.; Liu, T.; Hu, D.; Zhao, L. Antishrinking strategy of microcellular thermoplastic polyurethane by comprehensive modeling analysis. Ind. Eng. Chem. Res. 2021, 60, 7155-7166. [CrossRef]

29. Zhao, D.; Wang, G.; Wang, M. Investigation of the effect of foaming process parameters on expanded thermoplastic polyurethane bead foams properties using response surface methodology. J. Appl. Polym. Sci. 2018, 135, 46327. [CrossRef]

30. Cipriani, E.; Zanetti, M.; Brunella, V.; Costa, L.; Bracco, P. Thermoplastic polyurethanes with polycarbonate soft phase: Effect of thermal treatment on phase morphology. Polym. Degrad. Stab. 2012, 97, 1794-1800. [CrossRef]

31. Frick, A.; Rochman, A. Characterization of TPU-elastomers by thermal analysis (DSC). Polym. Test. 2004, 23, 413-417. [CrossRef]

32. Hossieny, N.J.; Barzegari, M.R.; Nofar, M.; Mahmood, S.H.; Park, C.B. Crystallization of hard segment domains with the presence of butane for microcellular thermoplastic polyurethane foams. Polymer 2014, 55, 651-662. [CrossRef]

33. Li, R.; Lee, J.H.; Wang, C.; Mark, L.H.; Park, C.B. Solubility and diffusivity of $\mathrm{CO}_{2}$ and $\mathrm{N}_{2}$ in TPU and their effects on cell nucleation in batch foaming. J. Supercrit. Fluids 2019, 154, 104623. [CrossRef]

34. Briscoe, B.; Zakaria, S. Gas-induced damage in elastomeric composites. J. Mater. Sci. 1990, 25, 3017-3023. [CrossRef]

35. Primel, A.; Férec, J.; Ausias, G.; Tirel, Y.; Veillé, J.M.; Grohens, Y. Solubility and interfacial tension of thermoplastic polyurethane melt in supercritical carbon dioxide and nitrogen. J. Supercrit. Fluids 2017, 122, 52-57. [CrossRef] 